\title{
It's been a long time coming, but it finally came
}

\author{
Michael K. Hsin, MD, FRCS, CTh
}

From the Department of Cardiothoracic Surgery, Queen Mary Hospital, Hong Kong.

Disclosures: Author has nothing to disclose with regard to commercial support.

Received for publication Feb 27, 2017; revisions received March 16, 2017; accepted for publication March 23, 2017; available ahead of print April 20, 2017.

Address for reprints: Michael K. Hsin, MD, FRCS, CTh, Department of Cardiothoracic Surgery, Room 308, 3/F

New Clinical Building, Queen Mary Hospital, 102 Pok Fu Lam Rd, Hong Kong (E-mail: mkhsin@ hotmail. com).

J Thorac Cardiovasc Surg 2017; 154:310-1

$0022-5223 / \$ 36.00$

Copyright (c) 2017 by The American Association for Thoracic Surgery

http://dx.doi.org/10.1016/j.jtcvs.2017.03.095

Sonett and colleagues ${ }^{1}$ wrote a comprehensive "Expert Opinion" on the Myasthenia Gravis Thymectomy Treatment (MGTX) trial. $^{2}$ To better appreciate the importance of the MGTX trial, the only prospective randomized controlled study comparing thymectomy with medical treatment, it is helpful to revisit the landscape before the MGTX trial.

In 2000, an evidence-based review on the role of thymectomy for myasthenia gravis (MG), from the American Academy of Neurology, concluded that the benefits of thymectomy in nonthymomatous MG has not been established conclusively. ${ }^{3}$ A critical analysis by Sonett and Jaretzki ${ }^{4}$ highlighted the main problems. First, life table analysis using the Kaplan-Meier method has been the preferred technique of analysis of remission after thymectomy and enables the calculation of hazard rates. However, this assumes that remission after thymectomy remains constant, which may not be the case in MG. Second, these retrospective studies did not address the variability and unpredictability of MG, the differing response to treatment among patients with different severities and subtypes of MG, and the patient selection bias. Third, remission was not uniformly defined, and quantitative scoring system was rarely applied. Other confounding issues include variations in immunosuppression regimen, inconsistencies in the duration of illness preoperatively and postoperative followup, inclusion of more than 1 surgical technique in the same series, inclusion of patients with thymoma or patients who had previous thymectomy, failure to report relapses, and failure to consider the rate of spontaneous remissions.

The MGTX trial included only patients aged 18 to 65 years, with clinical Myasthenia Gravis Foundation of America Class II to IV, and positive levels of acetylcholine receptor antibody. In these patients, over a 3-year period, an extended trans-sternal thymectomy resulted in greater improvement in the Quantitative Myasthenia Gravis score and the average prednisone requirement compared with the nonthymectomy group. Subgroup analysis showed that these benefits applied to women regarding the Quantitative Myasthenia Gravis score

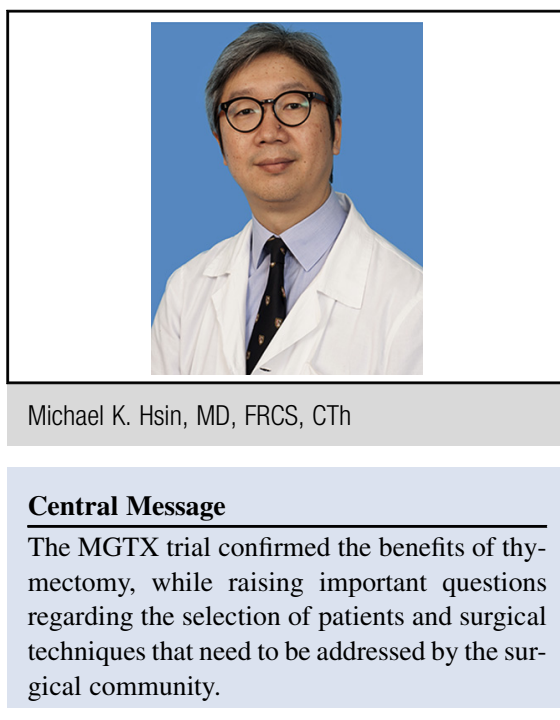

See Article page 306.

and prednisone dose, but in men there was only lowering of steroid dose. Patients who were steroid naive did not show a benefit.

It has been commented that although the improvement is clinically significant, in absolute terms the differences between groups are modest, patients in the thymectomy group still required a high average dose of prednisone, and the difference in rates of remission may decrease over time. ${ }^{5}$

A debate that started in the 1930s is finally settled by the MGTX trial. However, several important questions remain to be answered:

1. What is the long-term effect of thymectomy on the MG status, vis-a-vis future relapse?

2. What is the role of surgery in the current era, given the advances in the medical treatment for MG, such as the use of azathioprine to reduce the dose of prednisone, and new therapies such as rituximab and stem cell transplantation?

3. To what extent can the MGTX findings be applied to patients aged less than 18 years or who are acetylcholine receptor negative?

4. The MGTX trial mandated the use of extended transsternal thymectomy. The surgical community needs to determine whether alternative techniques, including transcervical, subxiphoid, video-assisted thoracoscopic surgery, and robotic approaches, can achieve results comparable to the extended trans-sternal approach. 


\section{References}

1. Sonett JR, Magee MJ, Gorenstein L. Thymectomy and myasthenia gravis: A history of surgical passion and scientific excellence. J Thorac Cardiovasc Surg. 2017; 154:306-9.

2. Wolfe GI, Kaminski HJ, Aban IB, Minisman G, Kuo HC, Marx A, et al. Randomized Trial of Thymectomy in Myasthenia Gravis. N Engl J Med. 2016; $375: 511-22$

3. Gronseth GS, Barohn RJ. Practice parameter: thymectomy for autoimmune myasthenia gravis (an evidence-based review): report of the Quality Standards Subcommittee of the American Academy of Neurology. Neurology. 2000;55:7-15.

4. Sonett JR, Jaretzki A III. Thymectomy for nonthymomatous myasthenia gravis: a critical analysis. Ann N Y Acad Sci. 2008;1132:315-28.

5. Ropper AH. RetroSternal-looking back at thymectomy for myasthenia gravis. N Engl J Med. 2016;375:576-7. 